\title{
THE FEAR OF COVID-19, DEMOGRAPHIC FACTORS, AND SUBSTANCE USE IN A MULTINATIONAL SAMPLE AMID THE COVID-19 PANDEMIC
}

\author{
IFEANYICHUKWU ANTHONY OGUEJI ${ }^{1}$, RACHEL BOLAJI ASAGBA ${ }^{1}$, DELROY \\ CONSTANTINE-SIMMS ${ }^{2}$ \\ ${ }^{I}$ Department of Psychology, Faculty of the Social Sciences, University of Ibadan, Ibadan, Oyo State, Nigeria \\ ${ }^{2}$ Think Doctor Psychological Assessments, Dubai, UAE and London, UK
}

(C) 2021 Ifeanyichukwu Anthony Ogueji, Rachel Bolaji Asagba, Delroy Constantine-Simms

This is an open access article distributed under the Creative Commons Attribution-NonCommercial-NoDerivs license (http://creativecommons.org/licenses/by-nc-nd/3.0/)

DOI: $10.1515 /$ eras-2021-0005

\begin{abstract}
The global pandemic caused by the coronavirus disease 2019 (COVID-19) had mental health consequences such as fear. Scholars have argued that when people are fearful, they may use substances to escape from fear, and demographic variables can have implications on how to target interventions to people. To date, little is known about how the fear of COVID-19 and demographic factors may contribute to substance use amid the COVID-19 pandemic. From 3 June to 10 June 2020, a cross-sectional study was conducted with 202 residents (Mean age = $41.77 \pm 11.85$; age range $=18-70$ years) in 14 countries. A standardized questionnaire was utilized for data collection, SPSS (version 22.0) was utilized for data analysis, and $\mathrm{p}<.05$ implied statistical significance. Descriptive statistics revealed that residents in Canada scored the highest mean score in the fear of COVID-19 scale, while residents in Australia scored highest in the substance use scale. Further, fear of COVID-19 had a negative nonsignificant relationship with substance use $(\mathrm{r}=-.07 ; \mathrm{df}=200 ; \mathrm{p}>.05)$. Males $($ Mean $=18.21)$ scored significantly higher than females (Mean $=14.06)$ in substance use [ $\mathrm{t}(200)=1.9 ; \mathrm{p}<.05]$. The younger age group (18-28 years) scored the highest mean score in substance use compared to older age groups (29-39 years, 40-50 years, 51-61 years, and 62-72 years); however, it was not significant $[\mathrm{F}(4,197)=2.04 ; \mathrm{p}>.05]$. These data contribute to informing future studies that add more questions regarding how different variables may contribute to substance use during subsequent waves of the COVID-19 pandemic.
\end{abstract}

\section{Keywords}

fear of COVID-19, COVID-19 pandemic, demographic factors, substance use, multinational sample

\section{Introduction}

The coronavirus disease 2019 (COVID-19) pandemic impacted the world in many ways; one of such is the fear instilled in many people (Rajkumar, 2020; World Health Organization, 2020). There is a strong consensus in the argument of scholars that during infectious disease outbreaks, fear or anxiety is a common consequence. For instance, Gardener and Moallef (2015) reported anxious concerns in patients who contracted severe acute respiratory syndrome (SARS). Also, the researchers reported anxious concerns in frontline workers and the general public during the SARS outbreak. Similarly, Maunder, et al. (2003) argued that anxiety was among the mental health concerns during the SARS outbreak. Some scholars reinforced the argument by identifying that fear or anxiety was commonly manifested in people during the SARS outbreak (Lau et al., 2005; Park, et al., 2018). In the same light, Chua and colleagues (2004) identified stressful and fearful concerns in the general public during 
the SARS outbreak. Further, mental health issues that are typical of fear and anxiety were reported during the Ebola outbreak (Acharibasam, et al., 2021; Ji, et al., 2017).

The above findings align with the current COVID-19 pandemic. For instance, Okoloba and colleagues (2020) found anxiety, fear, or worrisome concerns in a multinational sample (that is, participants from the United Kingdom, Netherlands, Norway, Singapore, Nigeria, United Arab Emirates, the United States of America, etc.) amid the COVID-19 pandemic. This was shared by other researchers that reported that fear, anxiety, and worrisome feeling were major psychological concerns for people amid the COVID-19 pandemic (Pakpour \& Griffiths, 2020). Similarly, Ahorsu, et al. (2020) submitted that fear and anxiety were among the impacts of the COVID-19 pandemic. Gao et al. (2020) reported high rates of anxiety among people in Wuhan, China due to the pandemic. In a sample comprising residents in the United States of America (USA), Israel, and others, Barzilay, et al. (2020) found anxiety and worrisome behaviors as among the consequence of the COVID-19 pandemic. Twenge and Joiner (2020) endorsed this by reporting high COVID-19-induced anxiety among 775 participants from the USA. Stanton, et al. (2020) found symptoms of anxiety among Australian adults $(n=1491)$ during the COVID-19 pandemic. Dozois (2020) surveyed a nationally representative sample of Canadians, and the results showed high anxiety levels in the sample. In the UK, Bennett, et al. (2020) reported anxiety symptoms among the UK general population during the COVID-19 pandemic. Verma and Mishra, (2020) found moderate to severe anxiety levels in the general Indian population during the COVID-19 pandemic. In Serbia, Marković, et al. (2020) submitted anxious concerns among participants in a survey study. A Nigerian study by Oyetunji, et al. (2021) found the presence of anxiety during the COVID-19 pandemic. A review paper argued the likely increase of psychiatric issues (e.g., anxiety) in the general South African population during the COVID-19 pandemic (Subramaney, et al., 2020).

The fear or anxiety experienced during the COVID-19 pandemic has the potential to initiate behavioral problems (Crescentini, et al., 2020; Harper, et al., 2020; Ornell, et al., 2020), particularly behavioral problems such as substance use (Dozois, 2020; Polakovic, et al., 2020; Rahman, et al., 2020; Wu, et al., 2008). However, to date, very scant data exist on the relationship between fear of COVID-19 and substance use. As the COVID-19 pandemic has affected over 200 countries (World Health Organization, 2020), it is very timely to research the fear of COVID-19 and substance use in a multinational sample. Further, international scholars argued that substance use is very likely to increase during the novel COVID-19 pandemic; however, they submitted that there is currently no research evidence to support their assertion (Lee, \& Bartle, 2020). In the same light, Franks (2020) opined that alcohol and drug use could rise during the COVID-19 pandemic because of people's desire to gain temporary escape from the fears caused by the pandemic; however, there are insufficient empirical studies to support this opinion.

The Canadian Centre on Substance Use and Addiction (2020) argued that substance use could increase with the ongoing COVID-19 pandemic due to increased stress and anxiety associated with the pandemic, and further research was needed to confirm this. Further, the Centre submitted from a Canadian survey that about 25\% of Canadians aged 35-54 years and about $21 \%$ of Canadians aged 18-34 years increased alcohol consumption amid the COVID-19 pandemic. Additionally, $10 \%$ of Canadians above age 54 years increased their alcohol consumption since the pandemic started, with most being males. Ogueji and colleagues (2021) added by reporting alcohol use among UK residents during the COVID-19 pandemic; however, the research was a qualitative one; therefore, it could not establish a significant linkage between fears associated with the COVID-19 pandemic and alcohol use. Given these data, theoretically, the current study drew insights from Lazarus and Folkman's (1984) stress and coping theory to argue that the fear of COVID-19 may have the potential to trigger substance use during the 
pandemic. The theory argues that when people encounter stress (e.g., the current COVID-19 pandemic), they may become fearful; therefore, they may employ coping strategies (e.g., substance use) to escape from fear. As a result, we expect that the fear of COVID-19 and substance use may be significantly positively associated.

Apart from the aforementioned, it is worth acknowledging that the literature documented that demographic information (e.g., gender and age) have implications on how to target substance use intervention programs to populations with various subpopulations (Adenugba \& Okeshola, 2018; Aina, et al., 2010; Anyanwu, et al., 2016; Asagba, et al., 2016, 2021; Bergen-Cico, \& Cico, 2017; Cho, et al., 2018; Constantine-Simms, et al., 2020; Debnam, et al., 2018; García-Fernández, et al., 2020; Johnson, et al., 2017; Kuerbis, et al., 2014; Olumide, et al., 2014; Rolland et al., 2020). Further, in the light of the COVID-19 pandemic, younger age groups (30-49 years) have reported increased substance use than their older counterparts in countries such as France (Rolland, et al., 2020). Therefore, the current study will also explore the demographic factors (gender and age) influencing substance use amid the COVID-19 pandemic.

Given the above, the following hypotheses were stated:

1. There will be a significant positive relationship between fear of COVID-19 and substance use amid the COVID-19 pandemic.

2. Male respondents will score significantly higher than female respondents in substance use amid the COVID-19 pandemic.

3. Younger age groups will score significantly higher than older age groups in substance use amid the COVID-19 pandemic.

\section{Method}

\section{Sampling and Respondents}

This was a cross-sectional research design. The independent variables were fear of COVID-19 and demographic variables (gender and age); whereas, the dependent variable was substance use. We recruited respondents using the snowball technique on Facebook (targeting various multinational groups). The virtual snowball technique implied that all recruited respondents were involved in the recruitment of potential respondents. The technique was most appropriate given the restricted movements during the COVID-19 pandemic. This research was approved by the Ethics Committee of the University of Ibadan, Ibadan, Oyo State, Nigeria.

A total of 202 respondents (mean age $=41.77 \pm 11.85$; age range $=18-70$ years) started and completed the survey (given hypothesis 3 , the ages of respondents were grouped; see Table 4). Of the 202 respondents, the distribution by country of residence showed; $1(0.50 \%)=$ Iceland, $1(0.50 \%)=$ India, $1(0.50 \%)=$ Indonesia, $1(0.50 \%)=$ Scotland, $1(0.50 \%)=$ Serbia, $1(0.50 \%)=$ South Africa, $1(0.50 \%)=$ The Netherlands, $2(0.99 \%)=$ Australia, $2(0.99 \%)=$ Brazil, $2(0.99 \%)=$ Mexico, $3(1.49 \%)=$ United States of America, $8(3.96 \%)=$ Canada, 10 $(4.95 \%)=$ England, and $168(83.17 \%)=$ Nigeria. Eighty-nine respondents were males and 113 respondents were females. Two hundred and one respondents had acquired tertiary education whereas 1 respondent had high school education. 


\section{Instruments}

A standardized questionnaire comprising three sections (A-C) was utilized for data collection (through Google Forms). The questionnaire was structured to fit into the COVID-19 pandemic context by asking respondents to respond to the questions in light of their experiences and behaviors since the COVID-19 pandemic started. Before the data collection, the intended questionnaire for data collection was subjected to expert validation (Krippendorff, 2013), and any disagreement was resolved (e.g., reworking the demographic section to align with the objectives of the current study).

Section A explored respondents' demographic information (including gender, age, highest educational qualification, and country of residence). Section B was the fear of the COVID-19 scale authored by Ahorsu, et al. (2020). It consisted of seven items responded on a 5-point Likert format ranging from strongly disagree to strongly agree. Illustrative items on the scale were; "I am most afraid of coronavirus-19", "My hands become clammy when I think about coronavirus-19", or "I cannot sleep because I'm worrying about getting coronavirus-19". The possible score on this scale ranged from 7-35. High scores were interpreted as a high fear of COVID-19, whereas low scores were interpreted as a low fear of COVID-19. Ahorsu, et al. (2020) reported a reliability coefficient of 0.82 for the scale as revealed by Cronbach's alpha. The current study reported a 0.89 reliability coefficient.

Given that we assessed the fear of COVID-19, it was possible that filling out the fear of COVID-19 scale could trigger more anxious concerns in respondents. Therefore, our online survey included statements that provided respondents with the contacts of free psychological helplines that offered services to clients from anywhere in the world. A statement that asked respondents to freely opt out of the study if filling out the fear of COVID-19 scale triggered anxious concerns was also included.

Section C measured general substance use with the drug use questionnaire (DAST-20) adopted from Skinner (2000). It consisted of 20 items, with a yes or no response pattern. Illustrative items on the scale were; "Have you used drugs other than those for medical reasons?", "Can you get through the week without using drugs?", or "Have you gone to anyone for help for a drug problem?" The scale author reported that no $=0$ and yes $=1$ for every item except items 4 and 5 that are reversed. The possible score on this scale ranged from $0-20$. High scores implied a high level of substance use, whereas low scores implied a low level of substance use. This scale author reported a reliability coefficient of 0.95 . For the current study, a reliability coefficient of 0.89 was reported.

\section{Data Collection Procedure and Process of Data Analysis}

All authors participated in the data collection. The survey link was weekly shared via the individual Facebook accounts of each author to permit access to respondents with varied sociodemographic information. The first page of the survey briefed respondents on the research purpose and elicited consent with an online consent form. Additionally, the first page assured respondents of their confidentiality; it also assured respondents that they were free to opt out of the research with no consequence if they chose so. The opportunities of self-report bias were minimized by sustaining respondents' anonymity throughout the study. Data collection was initiated on 3 June 2020 and ended on 10 June 2020. Only one response per respondent was allowed. Following data collection, the data were exported, cleaned, and analyzed using the Statistical Package for Social Sciences (SPSS version 22.0). Descriptive statistics were used to summarize the demographic characteristics and mean score (standard deviation) of respondents on all scales (see appendix). Appropriate inferential statistics were employed to test the hypotheses, and $p<.05$ was accepted as statistically significant. 


\section{Results}

\section{Hypothesis 1}

There will be a significant positive relationship between fear of COVID-19 and substance use amid the COVID-19 pandemic.

\section{Table 1}

\section{Pearson $r$ summary table showing the relationship between fear of COVID-19 and substance use amid the COVID-19 pandemic}

\begin{tabular}{lcl}
\hline & 1 & 2 \\
\hline 1 FOC & $\overline{07}$ & \\
2 SU & -.9 .59 & $\overline{17.13}$ \\
Mean & 19.73 & 6.58 \\
SD & 6.73 & \\
\hline
\end{tabular}

FOC $=$ Fear of COVID-19

$\mathrm{SU}=$ Substance use

The above result revealed that there was a negative relationship between fear of COVID-19 and substance use amid the COVID-19 pandemic at $(r=-.07 ; \mathrm{df}=200 ; \mathrm{p}>.05)$; however, the relationship did not attain statistical significance. The stated hypothesis that there will be a significant positive relationship between fear of COVID-19 and substance use amid the COVID-19 pandemic was, therefore, rejected in this study.

\section{Hypothesis 2}

Male respondents will score significantly higher than female respondents in substance use amid the COVID-19 pandemic.

\section{Table 2}

Independent sample t-test summary table comparing male and female respondents in substance use amid the COVID-19 pandemic.

\begin{tabular}{llllllll}
\hline DV & IV & N & M & SD & t & Df & p \\
\hline \multirow{2}{*}{ Substance use } & Male & 89 & 18.21 & 0.64 & & & \\
& & & & & 1.9 & 200 & $<.05$ \\
& Female & 113 & 14.06 & 0.52 & & & \\
\hline
\end{tabular}

The above table revealed that male respondents (18.21) scored a greater mean score when compared with their female counterparts (14.06) on substance use. Further, the difference was found to be statistically significant at $[\mathrm{t}(200)=1.9 ; \mathrm{p}<.05]$. The stated hypothesis that male respondents will score significantly higher than female respondents in substance use amid the COVID-19 pandemic was, therefore, accepted in this study. 
Ifeanyichukwu Anthony Ogueji, Rachel Bolaji Asagba, Delroy Constantine-Simms, The Fear of Covid-19, Demographic Factors, and Substance Use in a Multinational Sample Amid the Covid-19 Pandemic

DOI: 10.1515/eras-2021-0005

\section{Hypothesis 3}

Younger age groups will score significantly higher than older age groups in substance use amid the COVID-19 pandemic.

Table 3

One-way ANOVA summary table showing the difference in substance use across age groups.

\begin{tabular}{llllll}
\hline Source & SS & Df & MS & F & P \\
\hline $\begin{array}{l}\text { Between } \\
\text { group }\end{array}$ & 2.67 & 4 & 0.67 & & \\
$\begin{array}{l}\text { Within } \\
\text { group }\end{array}$ & 64.37 & 197 & 0.33 & 2.04 & $>.05$ \\
Total & 67.04 & 201 & & & \\
\hline
\end{tabular}

Results in Table 3 demonstrated that there was no significant difference in substance use across age groups as determined by one-way ANOVA at $[\mathrm{F}(4,197)=2.04$; p >.05]. Therefore, the stated hypothesis that younger age groups will score significantly higher than older age groups in substance use amid the COVID-19 pandemic was rejected in this study. Despite that there was no significant difference across age groups, we proceeded to post hoc analysis to explore which age group scored highest in substance use since a related study from France reported that younger age groups were more likely to use substances than older age groups amid the COVID-19 pandemic.

Table 4

Post hoc LSD summary table showing the mean difference in substance use across age groups

\begin{tabular}{lllllllll}
\hline Age Group & 1 & 2 & 3 & 4 & 5 & M & SD & N \\
\hline $18-28$ & - & & & & & 11.53 & 0.59 & 12 \\
$29-39$ & -0.45 & - & & & & 10.08 & 0.56 & 104 \\
$40-50$ & -0.31 & 0.15 & - & & & 11.23 & 0.55 & 29 \\
$51-61$ & -0.46 & -0.01 & -0.15 & - & & 9.07 & 0.61 & 43 \\
$62-72$ & -0.47 & -0.02 & -0.16 & -0.01 & - & 9.07 & 0.55 & 14 \\
\hline
\end{tabular}

Table 4 showed the result from the post hoc analysis on mean differences across age groups. Although not significant, the age group 18-28 years scored the highest mean score (11.53), while age groups 51-61 and 62-72 years scored the lowest mean score (9.07) in substance use. 


\section{Discussion}

We explored the influence of fear of COVID-19 and demographic variables on substance use amid the COVID-19 pandemic. Contrary to the stated hypothesis, the first result showed a negative nonsignificant relationship between fear of COVID-19 and substance use amid the COVID-19 pandemic. The result challenged the assertion of scholars that COVID-19induced fears may be significantly associated with substance use (e.g., Dozois, 2020; Franks, 2020; Lee, \& Bartle, 2020; Polakovic, et al., 2020; Twenge \& Joiner, 2020; The Canadian Centre on Substance Use and Addiction, 2020). The result challenged the result from an Australian study that indicated that, during the COVID-19 pandemic, fear and substance use were positively associated (Rahman, et al., 2020). Further, the result was a theoretical disagreement with the Lazarus and Folkman (1984) stress and coping theory employed in the current study. One implication of our first result is indicative of the need for large-scale studies exploring the association between fear of COVID-19 and substance use across countries.

Consistent with the stated hypothesis, the second result showed a significant gender difference in substance use amid the COVID-19 pandemic, with males scoring higher than females on the substance use scale. The result partly agreed with related studies that highlighted demographic variables (e.g., gender) as having implications for targeting substance use intervention programs to subpopulations (e.g., Adenugba \& Okeshola, 2018; Asagba, et al., 2016; Johnson, et al., 2017). The result partly supported studies that found that males may increase substance use during stress encounter (Debnam, et al., 2018).

On the other hand, our second result disagreed with a Spanish study that found no significant gender difference in substance use during the COVID-19 pandemic (GarcíaFernández, et al., 2020). Our result also disagreed with a study conducted with the general population of France that submitted that females were more likely than males to use substances during the COVID-19 pandemic (Rolland, et al., 2020). This disagreement may be explained by the multinational feature of our study. One possible implication of our second result is the need for substance use intervention programs amid the COVID-19 pandemic to target the male population over the female population. Future research should augment our second result by exploring the motives for the potential substance use in the male population during the COVID19 pandemic.

Contrary to our stated hypothesis, our third result revealed that although there was no significant age difference in substance use, younger respondents (18-28 years) scored the highest mean score in substance use amid the COVID-19 pandemic. This was almost similar to the submission of Rolland et al. (2020) that identified younger age to be significantly associated with increased alcohol use during the COVID-19 pandemic in France. Additionally, our third result almost supported a study that explored the effects of the COVID-19 outbreak on parents and children in Italy (Crescentini, et al., 2020). In that study, the researchers argued that during stress encounters, young people tend to employ maladaptive coping (e.g., substance use) more than older people often because of their immature coping abilities. Researchers in Japan also argued that due to being experienced, older age is associated with less confusion during stress encounter; therefore, increased likelihood of positive coping for older people, unlike younger people that are inexperienced (Nakatzato \& Shimonaka, 1989). It is, therefore, not surprising that our study found that younger respondents scored the highest mean score in substance use than older respondents amid the COVID-19 pandemic (however, it was a nonsignificant result). A possible implication of our third result is indicative of the importance of longitudinal studies exploring the age difference in substance use or maladaptive coping as the COVID-19 pandemic progresses. Therefore, we will carry out future longitudinal studies in this regard.

We conducted a descriptive analysis of respondents' country of residence against the fear of COVID-19 and substance use scales. Results revealed that residents in Canada scored 
the highest mean score in the fear of COVID-19 scale, while residents in Australia scored highest in the substance use scale. These findings may be explained by the increasing number of confirmed cases that were reported in these countries as at when the current study was conducted (COVID-19 National Incident Room Surveillance Team, 2020; World Health Organization, 2020). Overall, these data suggest the need for psychosocial interventions in every country affected by the COVID-19 pandemic.

Our findings must be interpreted within the methodological strengths and limitations. The fact that respondents had diverse countries of residence and a wide age range (18-70 years) are strengths of this study; however, countries of residence were not evenly distributed. Nevertheless, our study offers a multinational starting point for understanding the influence of fear of COVID-19 and demographic factors on substance use during the COVID-19 pandemic. Another limitation of the study was that we did not collect data on the history of substance use, as this variable could have implications for substance use during the pandemic.

The cross-sectional design of our study limited us from probing the changes in the pattern of substance use that may occur during subsequent waves of the COVID-19 pandemic. Also, causation among variables cannot be established with the cross-sectional design of our study. The use of the snowball sampling technique may have implications for sampling biases. Lastly, the self-report method of data collection may support response biases among respondents. However, we minimized response bias by utilizing an anonymous data collection form.

\section{Conclusion}

We concluded that gender difference in substance use amid the COVID-19 pandemic was significant in our multinational sample; whereas, fear of COVID-19 and age had no significant influence on substance use amid the pandemic, as found in our study. However, given our limited sample size, further studies are required to confirm the validity of our findings.

\section{Acknowledgment}

We are grateful to all respondents for giving up their time to fill out our survey. Finally, we are grateful to Dr. Olatunde Asagba and Dr. Samson F. Agberotimi for their contributions.

\section{Funding}

Professor. Rachel Bolaji Asagba (the second author) generously funded this study.

\section{Ethical consideration}

Our study followed the ethical standards of the National Health Research Ethics Committee, the Institutional Research Ethics Committee, and the 1964 Helsinki ethical declaration, its later amendment, or a comparable standard. We utilized an online consent form to obtain consent from all respondents, and all respondents consented that findings from their data should be published in this paper.

\section{Conflict of interest}

The authors have no conflict of interest to declare.

\section{Data availability statement}

The data associated with our study are available from the first author upon request. 


\section{Appendix}

\section{Distribution of respondents by country of residence and mean score on all scales}

\begin{tabular}{llll} 
Country & $\mathrm{N}(\%)$ & Fear of COVID Mean(SD) & Substance Use Mean (SD) \\
\hline Iceland & $1(0.50 \%)$ & 14 & 13.92 \\
India & $1(0.50 \%)$ & 21 & 4.75 \\
Indonesia & $1(0.50 \%)$ & 15 & 5.08 \\
Scotland & $1(0.50 \%)$ & 16 & 9.33 \\
Serbia & $1(0.50 \%)$ & 13 & 6.83 \\
South Africa & $1(0.50 \%)$ & 14 & 6.83 \\
Netherlands & $1(0.50 \%)$ & 14 & 5.75 \\
Australia & $2(0.99 \%)$ & $16(4.24)$ & $18.38(0.18)$ \\
Brazil & $2(0.99 \%)$ & $14(0.00)$ & $17.04(0.06)$ \\
Mexico & $2(0.99 \%)$ & $15.5(7.78)$ & $5.46(0.18)$ \\
United States & $3(1.49 \%)$ & $18(7.81)$ & $8.03(0.63)$ \\
Canada & $8(3.96 \%)$ & $23.5(4.44)$ & $8.36(0.65)$ \\
England & $10(4.95 \%)$ & $18(7.86)$ & $11.47(0.48)$ \\
Nigeria & $168(83.17 \%)$ & $19.87(6.81)$ & $9.08(0.55)$ \\
\hline
\end{tabular}

\section{REFERENCES}

Acharibasam, J. W., Chireh, B., \& Menegesha, H. G. (2021). Assessing anxiety, depression and insomnia symptoms among Ebola survivors in Africa: A meta-analysis. Plos One, 16(2), e0246515. https://doi.org/10.1371/journal.pone.0246515

Adenugba A. A., \& Okeshola, F. B. (2018) Substance abuse among females in Nigeria. International Journal of Business and Social Science, 9(5), 99-105. https://doi.org/10.30845/ijbss.v9n5p12

Ahorsu, D. K., Lin, C. Y., Imani, V., Saffari, M., Griffiths, M. D., \& Pakpour, A. H. (2020). The fear of COVID19 scale: development and initial validation. International Journal of Mental Health and Addiction, 1-9. https://doi.org/10.1007/s11469-020-00270-8

Aina, O. F., Oshodi, Y., \& Onajole, A. T. (2010) Substance use among secondary school students in an urban setting in Nigeria: Prevalence and associated factors. African Journal of Psychiatry 13, 52-57 https://doi.org/10.4314/ajpsy.v13i1.53430

Anyanwu, O. U., Ibekwe, R. C., \& Ojinnaka, N. C. (2016). Pattern of substance abuse among adolescent secondary school students in Abakaliki. Cogent Medicine, 1272160.https://doi.org/10.1080/2331205X.2016.1272160

Asagba, R. B., Chovwen, C. O., Alarape, A. I., \& Agberotimi, S. F. (2016). Psychosocial predictors of drug involvement among secondary school students. Journal of Social Sciences, 5(1), 7-12. https://journal.ibsu.edu.ge/index.php/jss/article/view/777/642

Asagba, R. B., Agberotimi, S. F., \& Olaseni, A. O. (2021). Prevalence and psychological correlates of alcohol use among Nigerian university students. Journal of Substance Use, 1-6. https://doi.org/10.1080/14659891.2021.1875067

Barzilay, R., Moore, T. M., Greenberg, D. M., DiDomenico, G. E., Brown, L. A., White, L. K., ... \& Gur, R. E. (2020). Resilience, COVID-19-related stress, anxiety and depression during the pandemic in a large population enriched for healthcare providers. Translational Psychiatry, 10(1), 1-8. https://doi.org/10.1038/s41398-020-00982-4

Bennett, K., Shevlin, M., McBride, O., Murphy, J., Gibson Miller, J., Hartman, T. K., ... \& Stocks, T. V. (2020). Anxiety, depression, traumatic stress, and COVID-19 related anxiety in the UK general population during the COVID-19 pandemic. British Journal of Psychiatry Open, 6(6). e125. http://doi.org/10.1192/bjo.2020.109

Bergen-Cico, D., \& Cico, R. D. (2017). Age as a predictor of cannabis use. In V. R. Preedy (Ed.), Handbook of cannabis and related pathologies: Biology, pharmacology, diagnosis, and treatment (p. 33-43). Elsevier Academic Press. 
Canadian Centre on Substance Use and Addiction (2020). Impacts of COVID-19 on substance use. https://ccsa.ca/Impacts-COVID-19-Substance-Use

Cho, J., Bhimani, J., Patel, M., \& Thomas, M. N. (2018). Substance abuse among older adults: A growing problem: Maintaining vigilance is the key to effective recognition and treatment. Current Psychiatry, 17, 14-21.

Chua, S. E., Cheung, V., McAlonan, G. M., Cheung, C., Wong, J. W., Cheung, E. P., ... \& Lee, P. W. (2004). Stress and psychological impact on SARS patients during the outbreak. The Canadian Journal of Psychiatry, 49(6), 385-390. https://doi.org/10.1177\%2F070674370404900607

Constantine-Simms, D., Ogueji, I. A., \& Asagba, R. B. (2020). Attitudes towards cough syrup abuse: results from adolescents in two Southwest states of Nigeria. Journal of Addictive Behaviors, Therapy, \& Rehabilitation, 9, 188. https://doi.org/10.37532/jabtr.2020.9(1).188

COVID-19 National Incident Room Surveillance Team. (2020). COVID-19, Australia: Epidemiology Report 18 (Fortnightly Reporting Period Ending 7 June 2020). Communicable Diseases Intelligence (2018), 44.

Crescentini, C., Feruglio, S., Matiz, A., Paschetto, A., Vidal, E., Cogo, P., \& Fabbro, F. (2020). Stuck outside and inside: an exploratory study on the effects of the COVID-19 outbreak on Italian parents and children's internalizing symptoms. Frontiers in Psychology, 11. https://doi.org/10.3389/fpsyg.2020.586074

Debnam, K. J., Milam, A. J., Mullen, M. M., Lacey, K., \& Bradshaw, C. P. (2018). The moderating role of spirituality in the association between stress and substance use among adolescents: Differences by gender. Journal of Youth and Adolescence, 47(4), 818-828. https://doi.org/10.1007/s10964-017-0687-3

Dozois, D. J. A., \& Mental Health Research Canada. (2020). Anxiety and depression in Canada during the COVID19 pandemic: A national survey. Canadian Psychology/Psychologie Canadienne, 62(1), 136-142. http://dx.doi.org/10.1037/cap0000251

Franks, I. J. (2020). Pandemic could lead to spike in alcohol and drug addiction. https://www.unthsc.edu/newsroom/story/pandemic-could-lead-to-spike-in-alcohol-and-drug-addiction/

Gao, J., Zheng, P., Jia, Y., Chen, H., Mao, Y., Chen, S., ... \& Dai, J. (2020). Mental health problems and social media exposure during COVID-19 outbreak. Plos One, 15(4), e0231924. https://doi.org/10.1371/journal.pone.0231924

García-Fernández, L., Romero-Ferreiro, V., López-Roldán, P. D., Padilla, S., \& Rodriguez-Jimenez, R. (2020). Mental health in elderly Spanish people in times of COVID-19 outbreak. The American Journal of Geriatric Psychiatry, 28(10), 1040-1045. https://doi.org/10.1016/j.jagp.2020.06.027

Gardener, P. J., \& Moallef, P. (2015). Psychological impacts on SARS survivors: Critical review of the English language literature. Canadian Psychology/Psychologie Canadienne, 56(1), 123-135. http://dx.doi.org/10.1037/a0037973

Harper, C. A., Satchell, L. P., Fido, D., \& Latzman, R. D. (2020). Functional fear predicts public health compliance in the COVID-19 pandemic. International Journal of Mental Health and Addiction, 27, 1-4. https://doi.org/10.1007/s11469-020-00281-5

Ji, D., Ji, Y. J., Duan, X. Z., Li, W. G., Sun, Z. Q., Song, X. A., ... \& Duan, H. J. (2017). Prevalence of psychological symptoms among Ebola survivors and healthcare workers during the 2014-2015 Ebola outbreak in Sierra $\begin{array}{llllll}\text { Leone: a } & \text { cross-sectional } & \text { Oncotarget, } & 8(8), & \end{array}$ https://dx.doi.org/10.18632\%2Foncotarget.14498

Johnson, O. E., Akpanekpo, E. I., Okonna, E. M., Adeboye, S. E., \& Udoh, A. J. (2017). The prevalence and factors affecting psychoactive substance use among undergraduate students in University of Uyo, Nigeria. Journal of Community Medicine and Primary Health Care, 29(2), 11-22.

Krippendorff, K (2013). Content analysis. An introduction to its methodology (3rd ed). California, Ca: Sage Publications.

Kuerbis, A., Sacco, P., Blazer, D. G., \& Moore, A. A. (2014). Substance abuse among older adults. Clinics in Geriatric Medicine, 30(3), 629-654. https://doi.org/10.1016/j.cger.2014.04.008

Lau, J. T., Yang, X., Pang, E., Tsui, H. Y., Wong, E., \& Wing, Y. K. (2005). SARS-related perceptions in Hong Kong. Emerging Infectious Diseases, 11(3), 417. https://dx.doi.org/10.3201\%2Feid1103.040675

Lazarus, R. S., \& Folkman, S. (1984). Stress, appraisal, and coping. Springer Publishing Company.

Lee, N., \& Bartle, J. (2020). Drug use may increase the risk of coronavirus. Here's how to reduce the harms. https://www.google.com/amp/s/theconversation.com/amp/drug-use-may-increase-the-risk-ofcoronavirus-heres-how-to-reduce-the-harms-135556.

Marković, I., Nikolovski, S., Milojević, S., Živković, D., Knežević, S., Mitrović, A., ... \& Đurđević, D. (2020). Public trust and media influence on anxiety and depression levels among skilled workers during the COVID-19 outbreak in Serbia. Vojnosanitetski Pregled, (00), 108-108. https://doi.org/10.2298/VSP200713108M

Maunder, R., Hunter, J., Vincent, L., Bennett, J., Peladeau, N., Leszcz, M., .. \& Mazzulli, T. (2003). The immediate psychological and occupational impact of the 2003 SARS outbreak in a teaching hospital. Canadian Medical Association Journal, 168 (10), 1245-1251. 
Nakazato, K., \& Shimonaka, Y. (1989). The Japanese state-trait anxiety inventory: age and sex differences. Perceptual and Motor Skills, 69(2), 611-617. https://doi.org/10.2466/pms.1989.69.2.611

Ogueji, I. A., Okoloba, M. M., \& Demoko Ceccaldi, B. M. (2021). Coping strategies of individuals in the United Kingdom during the COVID-19 pandemic. Current Psychology, https://doi.org/10.1007/s12144-02001318-7

Okoloba, M. M., Ogueji, I. A., Darroch, S. J., \& Ogueji, A. M. (2020). A multinational pilot study on the lived experiences and mental health impacts from the COVID-19 pandemic. Global Psychiatry, 3(2), https://doi.org/10.2478/gp-2020-0015.

Olumide, A. O., Robinson, A. C., Levy, P. A., Mashimbye, L., Brahmbhatt, H., Lian, Q., ... \& Blum, R. W. (2014). Predictors of substance use among vulnerable adolescents in five cities: findings from the well-being of adolescents in vulnerable environments study. Journal of Adolescent Health, 55(6), S39-S47. https://doi.org/10.1016/j.jadohealth.2014.08.024

Ornell, F., Schuch, J. B., Sordi, A. O., \& Kessler, F. H. P. (2020). "Pandemic fear" and COVID-19: mental health burden and strategies. Brazilian Journal of Psychiatry, 42(3), 232-235. https://doi.org/10.1590/15164446-2020-0008

Oyetunji, T. P., Ogunmola, O. A., Oyelakin, T. T., Olorunsogbon, O. F., \& Ajayi, F. O. (2021). COVID-19-related risk perception, anxiety and protective behaviours among Nigerian adults: a cross-sectional study. Journal of Public Health, 1-9. https://doi.org/10.1007/s10389-021-01502-4

Pakpour, A. H., \& Griffiths, M. D. (2020). The fear of COVID-19 and its role in preventive behaviors. Journal of Concurrent Disorders. https://concurrentdisorders.ca/2020/04/03/the-fear-of-covid-19-and-its-role-inpreventive-behaviors/

Park, J. S., Lee, E. H., Park, N. R., \& Choi, Y. H. (2018). Mental health of nurses working at a governmentdesignated hospital during a MERS-COV outbreak: A cross-sectional study. Archives of Psychiatric Nursing, 32(1), 2-6. https://doi.org/10.1016/j.apnu.2017.09.006

Polakovic, G. (2020). Pandemic drives alcohol sales and raises concerns about substance abuse. USC News. https://medicalxpress.com/news/2020-04-covid-alcohol-salesand-substance-abuse.html

Rahman, M. A., Hoque, N., Alif, S. M., Salehin, M., Islam, S. M. S., Banik, B., .. \& Cross, W. (2020). Factors associated with psychological distress, fear and coping strategies during the COVID-19 pandemic in Australia. Globalization and Health, 16(1), 1-15. https://doi.org/10.1186/s12992-020-00624-w

Rajkumar, R. P. (2020). COVID-19 and mental health: A review of the existing literature. Asian Journal of Psychiatry, 102066. https://doi.org/10.1016/j.ajp.2020.102066

Rolland, B., Haesebaert, F., Zante, E., Benyamina, A., Haesebaert, J., \& Franck, N. (2020). Global changes and factors of increase in caloric/salty food intake, screen use, and substance use during the early COVID-19 containment phase in the general population in France: Survey study. JMIR Public Health and Surveillance, 6(3), e19630. https://doi.org/10.2196/19630

Skinner, H. (2000) Drug Abuse Screening Test (DAST). Handbook of Psychiatric Measures. Washington, D.C.: American Psychiatric Association.

Stanton, R., To, Q. G., Khalesi, S., Williams, S. L., Alley, S. J., Thwaite, T. L., ... \& Vandelanotte, C. (2020). Depression, anxiety and stress during COVID-19: associations with changes in physical activity, sleep, tobacco and alcohol use in Australian adults. International Journal of Environmental Research and Public Health, 17(11), 4065. https://doi.org/10.3390/ijerph17114065

Subramaney, U., Kim, A. W., Chetty, I., Chetty, S., Jayrajh, P., Govender, M., ... \& Pak, E. (2020). Coronavirus disease 2019 (COVID-19) and psychiatric sequelae in South Africa: Anxiety and beyond. Wits Journal of Clinical Medicine, 2(2), 115-122. https://dx.doi.org/10.18772/26180197.2020.v2n2a2

Twenge, J. M., \& Joiner, T. E. (2020). US Census Bureau assessed prevalence of anxiety and depressive symptoms in 2019 and during the 2020 COVID-19 pandemic. Depression and Anxiety, 37(10), 954-956. https://doi.org/10.1002/da.23077

Verma, S., \& Mishra, A. (2020). Depression, anxiety, and stress and socio-demographic correlates among general Indian public during COVID-19. International Journal of Social Psychiatry, 66(8), 756-762. https://doi.org/10.1177\%2F0020764020934508

World Health Organization. (2020). Coronavirus disease 2019 (COVID-19): situation report, 82.

World Health Organization. (2020). Advice on the use of masks in the context of COVID-19: interim guidance, 5 June 2020 (No. WHO/2019-nCov/IPC_Masks/2020.4). World Health Organization.

Wu, P., Liu, X., Fang, Y., Fan, B., Fuller, C. J., Guan, Z., ... \& Litvak, I. J. (2008). Alcohol abuse/dependence symptoms among hospital employees exposed to a SARS outbreak. Alcohol \& Alcoholism, 43(6), 706712. https://doi.org/10.1093/alcalc/agn073 